\title{
NECESSIDADES EDUCACIONAIS ESPECIAIS E A PEDAGOGIA, EM TRÊS MOMENTOS DE FORMAÇÃ ${ }^{1}$
}

SILVA, Claudionor Renato da

Rua Vicenzo Spoto, 32, Jardim Maria Luiza. Pedagogo e Mestrando em Educação. Universidade Federal de São Carlos - UFSCar. E-mail: claudionorsil@gmail.com

ROSA, Juliene de Cássia Leiva

Docente do Departamento Ciências Humanas e Sociais do Centro Universitário de Araraquara - Uniara.

\section{RESUMO}

Este artigo apresenta e discute três momentos da formação inicial de pedagogos na temática da inclusão e diversidade, tendo como foco as necessidades educacionais especiais. A metodologia qualitativa do estudo de caso foi utilizada nos três momentos da pesquisa. Nos dois primeiros momentos o instrumento utilizado para a coleta de dados foi um texto e no terceiro momento, a aplicação de questionário semi- estruturado. Os dois primeiros momentos ocorreram no início e no final do ano de 2008 e o terceiro momento, seis meses depois. Os resultados apontaram o amadurecimento profissional e pedagógico dos entrevistados, principalmente na desconstrução de mitos, medos e opiniões de senso comum relacionados à educação especial e à inclusão escolar, ao mesmo tempo em que novas construções e saberes sobre essas temáticas foram sendo organizados nas suas representações. Os indicadores quantitativos demonstraram uma considerável sedimentação das ideias e conceitos fundamentais da educação especial e inclusão, bem como da prática da inclusão escolar, condição imprescindível para que se efetive na escola uma real educação na diversidade, com qualidade e profissionalismo de um de seus principais atores de mudança: o professor.

Palavras-chave: Necessidades educacionais especiais; Formação de educadores; Inclusão; Diversidade; Pedagogia.

\begin{abstract}
This paper presents and discusses three moments in educators'initial formation in diversity and inclusion themes, focusing special educational needs. The qualitative methodology of case study was used in the threemoments of the research. In the first two moments the instrument used for data collecting was a text and, in the third moment, a semi-structured questionnaire. The first two moments took place at the beginning and at the end of 2008 and the third moment took place 6 month later. The results showed the professional and pedagogical maturing of the interviewed participants, mainly in the deconstruction of myths, fears and opinions based on the common sense related to special education and school inclusion, at the same time as new construction and knowledge about these themes were organized in their representations. The quantitative indicators have demonstrated a considerable sedimentation of the ideas and fundamental concepts in special education and inclusion, as well as of the practice of school inclusion, a necessary condition for the realization in school of a true education in diversity, with quality and professionalism of one of its main actors of change: the teacher.
\end{abstract}

KEYwORDS: Special educational needs; Educator formation; Inclusion; Diversity; Pedagogy.

Os resultados desta etapa da pesquisa foram apresentados no III Congresso Brasileiro de Educação Especial na UFSCar (Universidade de São Carlos) em dezembro de 2008. Os dados desta pesquisa completa, no IV EIDE (Encontro Iberoamericano de Educação) na FCLar/UNESP, em Araraquara, em novembro de 2009. 


\section{INTRODUÇÃo}

A temática da educação de pessoas com necessidades educacionais especiais $\left(\mathrm{NEE}^{2}\right)$ na educação básica tem ganhado ampla repercussão discursiva, no âmbito das políticas públicas educacionais, das pesquisas acadêmicas, das práticas docentes, do dia a dia da escola, como também e, fundamentalmente, nas universidades formadoras de professores, portanto, das licenciaturas.

$\mathrm{Na}$ licenciatura em Pedagogia, em sua nova "roupagem" curricular nacional, é que a temática da educação nas NEE toma dimensões complexas, advindas, sobretudo, do ideal da educação para todos, da inclusão, da diversidade, da pluralidade cultural (multiculturalismo) - dentre outros conceitos e concepções - pautados no paradigma da pósmodernidade e da teoria da complexidade moriniana ${ }^{3}$.

Nesse sentido, a formação de professores, tanto inicial como em serviço (chamada de formação continuada), é a grande preocupação e o foco das discussões atuais, tendo o crivo da diversidade como elemento articulador por uma educação - ou sistema educacional-que "inclua" pessoas com NEE nas salas de aula "comuns" da educação básica.

As palavras "incluir" e "comuns" são alguns dos "nós" que perpassam a formação de professores, nos cursos de licenciatura em Pedagogia. As questões que se instauram são: a escola e, por consequência, a democracia, em essência, é inclusiva, se temos que "incluir", então, não temos escola, nem democracia. Por outro lado, o que são salas "comuns"? Pessoas com NEE são incomuns? Não são pessoas?

Essas são algumas das questões que a presente pesquisa procurou investigar, tendo como pressupostos a Educação Especial e a formação de professores nos cursos de Pedagogia.

A pesquisa é resultado de um trabalho de Iniciação Científica iniciado no ano de 2008, finalizado no primeiro semestre de 2009, cujo enfoque foi detectar as representações dos pedagogos em formação inicial, quanto à educação especial e à inclusão escolar, considerando desde concepções subjetivas até as teóricas, voltadas à educação de pessoas NEE, nas salas regulares da educação básica, nos anos iniciais do Ensino Fundamental.

\section{REFERENCIAL TEÓRICO: A FORMAÇÃO DE PROFESSORES E INCLUSÃO}

Michels (2008) usa uma palavra chave para a questão da formação de professores para a educação inclusiva, na diversidade: ambiguidade.

Tal ambiguidade gera indefinição, a ponto de se verificar em pesquisas de formação de professores, alguns posicionamentos de senso comum, embora esses professores tenham passado pelos bancos de instituições de ensino superiores.

Esses posicionamentos acabam por se "naturalizar" dos discursos (falas) docentes para a práxis educativa constituindo-se em um "habitus"4 que deve ser superado, no sentido da construção de novas posturas, de saberes tanto de cunho profissional como educacional e também didático-pedagógico.

Com o fim das habilitações nos cursos de Pedagogia pela legislação nacional vigente ${ }^{5}$, as habilitações em gestão escolar, educação especial, dentre outras, terão seus profissionais formados em cursos de pósgraduação.

\footnotetext{
${ }^{2} \mathrm{~A}$ partir daqui o texto trará apenas a sigla NEE.

${ }^{3}$ Referencia a Edgar Morin e à sua teoria da complexidade para compreensão e apreensão do conhecimento e da ciência. ${ }^{4}$ Conceito de Bourdieu, elaborado e reelaborado ao longo de sua extensa produção acadêmica como sociólogo, com extensas contribuições à educação. Definição: "um sistema de disposições duráveis e transponíveis que, integrando todas as experiências passadas, funciona a cada momento como uma matriz de percepções, de apreciações e de ações (...) (BOURDIEU, 1983, p. 65).

${ }^{5}$ Ver BRASIL. Conselho Nacional de Educação. Conselho Pleno. Resoluçãon ${ }^{\circ}$ 1, de 15 de maio de 2006, que institui as Diretrizes curriculares nacionais para o curso de graduação em Pedagogia, licenciatura. Brasília, 2006.
} 
Mas, como afirma Michels (2008), tal enunciado legal não exime - e isto é fundamental e imprescindível que se afirme - os cursos de graduação de discutirem a temática da educação especial e inclusiva:

Nas Diretrizes para o Curso de Pedagogia que institui Diretrizes Curriculares Nacionais para o Curso de Graduação em Pedagogia, licenciatura (Brasil, 2006) onde as habilitações são extintas, a formação desses professores é reafirmada (em nível superior) uma vez que indica que deve garantir-se a discussão sobre a educação de pessoas com necessidades especiais na formação geral dos professores (MICHELS, 2008, p.240).

A temática da formação de professores para a inclusão é um dos fatores mais importantes a serem considerados especialmente quando se conjecturou a política pública da inclusão de estudantes com NEE nas salas regulares marcadamente superlotadas, sem estrutura mobiliária adequada e outros problemas somados ao problema maior que era - e, ainda é toda uma classe ou geração de professores que não tiveram em sua formação, seja inicial ou em serviço, a temática da inclusão, da diversidade, da educação especial.

Oliveira e Costa (2003) afirmam que

Lidar com a diversidade no cotidiano escolar, para educadores que adquiriram em sua formação os conceitos de desejabilidade da homogeneidade grupal e de prontidão para a aprendizagem, por exemplo, é especialmente difícil. Eles perseguem o mito da performance ideal e da normalidade em sentido pleno (OLIVEIRA E COSTA, 2003, p.100).

Portanto, há que ser considerada com muito cuidado e perspicácia acadêmica uma proposta de formação inicial em Pedagogia que opere essas relações ao mesmo tempo em que considerações de profissionalismo pedagógico direcionado para competências e habilidades desconstruam esse ideário homogeneizador, colocando-o sobre rasuras.

O que entendemos, a partir desta pesquisa, com um olhar sobre os trabalhos de Gomes e Rey (2008), Oliveira e Costa (2003), Tinos, Orlando e Denari (2008) e Pereira e Mendes (2003) é que não basta detectarmos os entraves, conflitos e a complexa trama das realizações e idealizações da escola inclusiva, particularmente, da formação de professores. É preciso ir além. Considerar essas representações para, a partir delas, formular práticas diretivas de (re) formulações de currículos, inovações práticas e, especialmente, a mudança de discursos de senso comum para fundamentações teórico- práticas.

Esta seria a superação do senso comum profissional, presente em muitas das pesquisas de formação de professores na temática da diversidade e da inclusão.

Suas representações devem ser consideradas, contudo não supervalorizadas em detrimento dos atores envolvidos que mais necessitam ser focados: os estudantes da educação básica.

Considerar exclusivamente e somente as representações perpetuará o ciclo das desigualdades, dos preconceitos e da barbárie educacional marcada pelo preconceito, tabus e ambiguidades. E como nos indica Adorno (2006):

Mudanças de fundo exigem pesquisas acerca do processo da formação profissional (...) Mas não se deve esquecer que a chave da transformação decisiva reside na sociedade e em sua relação com a escola. Enquanto a sociedade gerar a barbárie a partir de si mesma, a escola tem apenas condições mínimas de resistir a isto (...) Mas se a barbárie, a terrível sombra sobre a nossa existência, é justamente o contrário da formação cultural, então a desbarbarização das pessoas individualmente é muito importante. A desbarbarização da humanidade é o pressuposto imediato da sobrevivência. Este deve ser o objetivo da escola, por mais restritos que sejam seu alcance e suas possibilidades (ADORNO, 2006, p. 116-7). 
Portanto, consideramos diversidade, nesse trabalho, a acepção adotada em Brasil (2006), Pereira e Mendes (2003) e Oliveira e Costa (2003), cujo enfoque é a formação de professores para atender educandos com NEE.

Cabe também a consideração do uso do termo "representações" como encaminhamento de pesquisa, conforme desenvolvido por Gomes e Rey (2007) e Oliveira e Costa (2003): produção de sentidos, significados e emotividades, traduzidos em medos, insegurança, preconceitos, frustrações, incapacidades e até críticas ao sistema educacional vigente, mas especialmente, defesas docentes (justificativas para o não enfrentamento ou negação).

Sobre essas defesas docentes Oliveira e Costa (2003) afirmam que

Estas defesas consubstanciam-se, em nosso entendimento, nas representações que elaboram sobre sua identidade, o seu "fazer" docente (...) Transitaremos, portanto, do ser - emoções, motivação, defesas, subjetividade - para o fazer (...). (OLIVEIRA E COSTA, 2003, p.99).

\section{ObJetivo}

Considerando a atualidade e a urgência do tema quanto às preocupações com a formação de professores nas licenciaturas em Pedagogia; considerando ainda os referenciais aqui abordados para a compreensão da diversidade e das representações, a presente pesquisa buscou construir uma interpretação dos processos que desencadeiam, no espaço de formação inicial, as concepções de educação nas NEE, no contexto de um componente curricular voltado para a reflexão na temática da educação especial.

\section{Metodologia}

Utilizamos a metodologia do estudo de caso, conforme propostas de André (2005), Sobrinho e Naujorks (2001) para os três momentos desta pesquisa.

$\mathrm{O}$ instrumento selecionado para a coleta de dados nas duas primeiras etapas foi um texto produzido pelos alunos e, para a última, a aplicação de questionário semiestruturado.

No primeiro momento buscamos identificar as representações iniciais dos entrevistados que começavam a estudar o primeiro componente curricular do curso de Pedagogia referente às questões da educação na diversidade, à educação especial e à inclusão.

Ao término do ano letivo, com a devolutiva das produções realizadas no início do ano, fizemos a proposta para que os entrevistados registrassem suas mudanças de posições ou idéias (representações), caso houvesse.

O último momento desta pesquisa foi a aplicação de um questionário semiestruturado sobre aspectos voltados à sedimentação dos conceitos, identificação dos diversos tipos de NEE e considerações mais abrangentes sobre a efetivação de uma escola inclusiva com qualidade de ensino para todos.

Sistematizando e sintetizando os três momentos, temos:

- $1 .^{\circ}$ momento: uma produção textual individual abordando duas considerações: o que fariam se tivessem em sua sala um (s) aluno ( $\mathrm{s}$ ) com NEE e o que entendiam por Educação Especial.

- 2. ${ }^{\circ}$ momento: devolução das produções do início do ano, relatando mudanças de posicionamento ou apontando novas aprendizagens.

- 3. momento: aplicação de um questionário semiestruturado envolvendo os seguintes tópicos: caracterização dos entrevistados, noções e conceitos básicos, vivências em educação especial e percepções sobre a formação de professores.

Os participantes desta pesquisa foram estudantes do $3 .^{\circ}$ Ano de Pedagogia de uma universidade privada do interior de São Paulo, no contexto do componente curricular "Educação e Inclusão".

Tal componente é o único do Curso a tratar especificamente da temática, juntamente com Libras (Língua Brasileira de Sinais, oferecido no último ano do curso. Os componentes curriculares articulados Desenvolvimento Humano e Psicologia e Educação contemplam parcialmente a temática. 
Os Resultados da PESQuisa: APRESENTAÇÃo E DISCUSSÃO DOS TRÊS MOMENTOS

Nossa busca em cada etapa da pesquisa foi a de encontrar, nas representações dos entrevistados, construções e desconstruções ao longo do processo de formação, pois como afirma Gomes e Rey (2007):

Até então, muito pouco se explorou aquilo que, de fato, os agentes humanos envolvidos, entre eles os profissionais da educação, realmente sentem quando passa a fazer parte da rotina escolar um aluno atípico em relação aos demais, em decorrência de seus déficits mentais, físicos ou sensoriais, e que sentidos cercam seus posicionamentos frente a esse novo aluno (GOMES e REY, 2007, p.409).

Sobre o perfil dos entrevistados: $64 \%$ tinham entre 18 e 27 anos; $27 \%$, aproximadamente, entre 28 e 48 anos. Dentre os entrevistados, 67\% atuavam na área da educação, como professores e agentes de educação (monitores, auxiliares, estagiários remunerados, etc.). Cerca de 55\% afirmaram já terem trabalhado ou vivenciado uma situação de atividade profissional, envolvendo educandos com NEE.

\section{Primeiro momento}

Este momento caracterizou-se pela produção de um texto livre que discorresse sobre duas questões principais: a primeira indagava sobre o que os entrevistados entendiam/conheciam sobre educação especial e inclusão; a segunda questão referia-se à hipótese de, caso fossem professores em uma sala de aula regular, como agiriam se recebessem um ou mais alunos com NEE.

Dos 56 participantes da entrevista no início do ano letivo (2008) obtivemos a produção de 53 textos referentes à primeira questão e 129 textos à segunda questão.

O que se depreende desse primeiro momento é que a preocupação dos professores em formação inicial parece estar mais voltada para a prática docente do que para o conceito ou posição sobre a educação especial, diversidade e inclusão escolar. O que é natural e evidente dado que esse componente curricular é o primeiro na formação desses entrevistados.

Todas as respostas tanto para a primeira como para a segunda questão foram organizadas em categorias. $\mathrm{Na}$ primeira questão as três categorias que mais apareceram dentre as onze foram: 1) Desafio (medo, insegurança); 2) Favoráveis à inclusão (caminho sem volta, educação para todos) e 3) situação preocupante e alguns relatos de práticas vivenciadas. Somados esses posicionamentos, atingiram em torno de $70 \%$ das respostas produzidas, indicando a presença de uma carga de senso comum nas representações desses entrevistados.

Na segunda questão pôde-se verificar que a grande maioria dos entrevistados receberia normalmente aluno(s) comNEE e sua primeira atitude seria identificar a NEE, envolver esse aluno com a sala e observá-lo (juntas, essas representações somam $65 \%$ das respostas totais). Percebe-se uma certa falta de direção quanto ao trabalho numa situação inclusiva o que implica também uma análise mais apurada sobre tal posicionamento, como defende Omote (2004), pois talvez essa simples aceitação na sala de aula não se configure uma inclusão efetiva tal como se pretende. Deixar na sala de aula regular o aluno com NEE ou retirá-lo num dado momento para uma sala de recursos é manter a exclusão e mascarar uma inclusão que não existe de fato, mas que se finge existir.

Essas representações "exigem novos posicionamentos a fim de reconstruir as práticas educativas oferecidas" (GOMES e REY, 2007, p. 408).

\section{Segundo momento}

Ao final do ano letivo foi realizada uma devolutiva aos entrevistados propondo que, voluntariamente, discorressem se mudaram de posicionamentos quanto à educação especial e inclusão ou se mantinham as mesmas proposições iniciais. Os resultados dessa etapa, com a devolutiva de apenas dez entrevistas, demonstraram que, de alguma maneira, quando se retira a possibilidade de "cobrança" num contexto de componente curricular, o grau de participação cai, revelando que a temática não ocupa uma atenção 
particular ou prioritária para a formação. Seria o "habitus" de Boudieu fincado nas características de formação docente e um dos tabus do magistério na alegoria adorniana para discussão da formação docente.

Contudo, a participação dos dez entrevistados demonstra alguns aspectos importantes nesse processo de formação inicial. O principal deles é a verificação de que três mudaram de opinião, indicando que a representação inicial marcada por medo, desafio, insegurança, que representaram cerca de $70 \%$ das respostas no início do ano letivo, foram superadas, conforme o Quadro 1.

\begin{tabular}{|c|c|}
\hline \multicolumn{2}{|c|}{ REPRESENTAÇÕES MUDADAS/ACRESCENTADAS } \\
\hline $\begin{array}{l}\text { Início do ano letivo (2008) } \\
\text { - “Acho que é algo que assusta um pouco no primeiro momento, } \\
\text { por não estar acostumada com a situação ou não estar preparada } \\
\text { didaticamente...” }\end{array}$ & $\begin{array}{l}\text { Devolutivas (ao final do ano) } \\
\text { - "Só mudaria o início em que digo que ficaria amedrontada } \\
\text { com situação de ter em minha sala uma criança que necessite de } \\
\text { educação especial..." } \\
\text { - "Apenas ratificar que o papel docente voltado para as NEE } \\
\text { devem ser presentes em toda a Educação Básica e não somente } \\
\text { nos Anos Iniciais". (Uma representação "acrescida"). } \\
\text { - Só não ficaria tão preocupada, pois a inclusão já não me dá } \\
\text { muito medo. Me sinto um pouco mais segura e confiante diante } \\
\text { desse desafio". }\end{array}$ \\
\hline
\end{tabular}

Quadro 1 - Representações das devolutivas dos entrevistados.

Como se observa, o universo dos entrevistados que participaram da devolutiva e que havia inicialmente se referido à inclusão com representações de medo, insegurança, falta de capacidade, etc., foi desconstruído por pelo menos dois deles, um número realmente bem inferior aos demais participantes (7) que afirmaram não ter mudado de posição.

A representação acrescida que afirma a educação especial com enfoque real para toda educação básica indica de alguma forma uma questão que apareceu no terceiro momento da pesquisa quando os entrevistados opinaram sobre a importância do componente curricular na temática da educação especial e inclusão nas demais licenciaturas que tratam das especialidades como Língua Portuguesa, Matemática, História, etc.
Quanto aos outros sete participantes, cinco ou reescreveram o que haviam escrito no início do ano letivo (um entrevistado), ou apenas assinalaram "Sim" na folha de atividade, indicando que permaneciam com a mesma representação do primeiro momento da pesquisa.

Contudo, os dois outros restantes trouxeram grandes contribuições à pesquisa, pois, embora mantivessem as representações do início do ano letivo, apresentaram respectivamente um relato pessoal de atividade em serviço e uma colocação sobre questões ainda não resolvidas mesmo com todas as discussões e esclarecimentos proporcionados pelo componente curricular durante o ano.

O relato é apresentado a seguir: 
Mesmo mantendo a minha resposta quero dizer que tentei por oito meses trabalhar com esse aluno e confesso que tive resultados positivos com ele. Exemplo: ele se tornou meu amigo e eu amiga dele. Suas aulas foram benéficas no meu relacionamento com ele. Essa criança ficou menos agressiva, conseguia realizar algumas atividades. Procurei psicóloga e fonoaudióloga da Prefeitura. Prometeram me ajudar e nunca apareceram. Infelizmente na metade de outubro me mudaram de turma e com a chegada da nova professora tudo voltou como era antes.Quem perdeu foi o garoto (ENTREVISTADO 4).

O entrevistado fez referência no início do ano sobre sua experiência com um aluno surdo-mudo. Encontrou dificuldades em sua ação docente, pois viu sua sala se dispersar e esse aluno tornar-se o centro de tudo, ficando os demais "perdidos". Como se vê o entrevistado faz apontamentos importantes quanto ao fato de que sua prática melhorou com o processo de (novas) construções e saberes docentes inclusivos.

Já o entrevistado 9 fez o pedido de um esclarecimento sobre casos específicos de inclusão como, por exemplo, deficiência múltipla (uso de sonda). Acreditamos não termos encontrado algumas respostas para muitos problemas na educação, bem como em outras áreas do conhecimento. Não é diferente na educação especial, área na qual algumas respostas ainda estão sendo formuladas pela academia. O que há de concreto, o que equivale dizer, o que deve ser feito, está diante de nossos olhos: devemos nos posicionar enquanto atores políticos da mudança ideológica do sistema de ensino vigente e pela prática com aporte teórico buscarmos soluções nesse grande laboratório educacional que é a sala de aula.

\section{Terceiro momento}

Com a participação de 36 entrevistados, o questionário semiestruturado, aplicado entre maio e junho de 2009, com o mesmo universo da pesquisa dos dois primeiros momentos foi organizado em quatro eixos principais: perfil dos entrevistados, conceitos básicos em educação especial e inclusão, vivências na educação especial e percepções sobre a formação em Pedagogia.

No item que trata dos conceitos básicos e "inclusão educacional", 86\% dos entrevistados afirmaram acreditar num processo educacional emque alunos com NEE participam ativamente. Isso demonstra fundamentalmente que os pedagogos em formação assimilaram o compromisso político e pedagógico com a inclusão que como afirma Bueno (2008) necessitam de maior aprofundamento especialmente no que concerne às políticas públicas.

Para o conceito de educação especial, 69,4\% afirmaram ser uma área de formação para educadores que atuarão com alunos com NEE. Os $22 \%$ que afirmaram ser uma educação diferente parecem não ter apreendido a definição.

A Figura 1 apresenta a posição dos entrevistados quanto aos momentos do curso em que foram discutidas questões referentes à educação especial e inclusão.

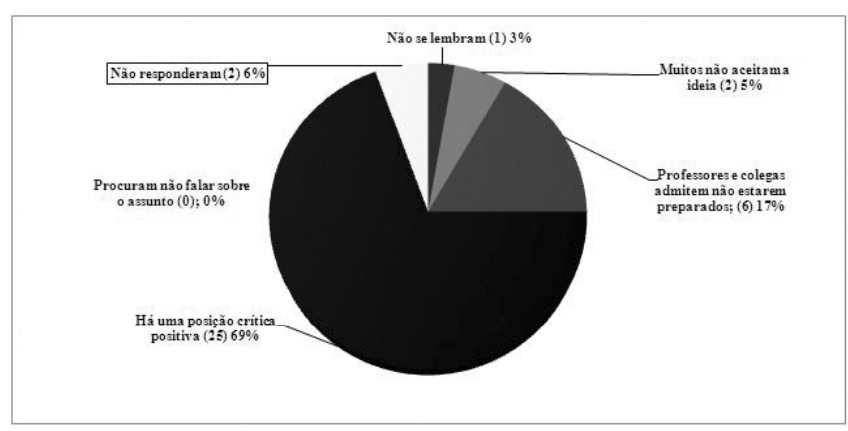

Figura 1 - Discussões sobre a inclusão e a diversidade em vários momentos do curso.

De acordo com a figura 1, destaca-se a opção (69\%) em que professores e colegas, ao discutirem a questão em outros momentos dos componentes curriculares, o fizeram de forma positiva, comprovando as posições de Skliar (2001) para quem a temática da educação especial é uma temática da educação.

Com relação aos estágios supervisionados na área, $67 \%$ afirmaram que gostariam de realizá-los caso 
estivessem incluídos na grade do curso. Outros 89\% foram favoráveis à inclusão, na estrutura do Curso de Pedagogia, de estágios na área. Essas opiniões sobre a necessidade de estágios específicos estão de acordo com os $44 \%$ dos entrevistados que afirmaram que a formação inicial voltada às questões da educação especial, inclusão e diversidade supõe, além de leituras e reflexões, ações teórico-práticas e multidisciplinaridade.

Esses resultados demonstram os caminhos possíveis para a inclusão escolar de qualidade a começar nas estruturas de formação. Mesmo com as ambiguidades da lei e das estruturas sociais refletidas no sistema escolar, é possível novas construções no sentido da superação do preconceito e na construção de alternativas para o educar na diversidade. Esse terceiro momento da formação inicial desses pedagogos indica essa(s) possibilidade(s).

\section{Apontamentos reflexivos}

Dada a especificidade da presente pesquisa que se direciona para um olhar em processo, no contexto da formação inicial em Pedagogia, por todo um ano e seis meses após a conclusão do componente curricular do curso, reforça-se o que outros estudos já apontaram (BUENO, MENDES E SANTOS, 2008), que o fator formação inicial e continuada é imprescindível para o processo de afirmação da educação inclusiva.

Um componente curricular que se articule e culmine numa prática didático-pedagógica possível para a sedimentação de conceitos educacionais nas NEE orientados a uma prática solidificada, norteadora nos processo de ensino e de aprendizagem na diversidade.

Ademais, um componente curricular que operacionalize (1) desconstruções de senso comum, de ideologias, preconceitos e medos ao mesmo tempo em que se efetuam e se solidificam construções profissionais, epistemológicas e práticas; (2) o amadurecimento profissional e de formação inicial no tocante à prática pedagógica futura e os desafios da educação, particularmente da profissão professor.

Do primeiro para o segundo momento da pesquisa percebe-se que uma parcela representativa considerável construiu uma nova percepção (representação) sobre a idéia da inclusão mesmo tendo obtido um retorno de apenas dez textos.

Nessas devolutivas não foram citadas conceituações de educação especial e inclusão, embora tenham aparecido as palavras "educação especial" e "necessidades educacionais especiais". Os conceitos vão aparecer no momento seguinte da pesquisa, com a aplicação do questionário. Portanto, essas representações devolutivas restringiram-se a aspectos voltados à prática docente desses futuros professores.

Para uma formação que se pretende inclusiva, não basta, não é suficiente uma construção de visões sobre a inclusão. É preciso avançar.

Outra observação importante na devolutiva é que não houve uma referência a questões ligadas à prática docente na atuação com estudantes com NEE, embora apareça, no terceiro momento da formação, que os estudos em Educação Especial e inclusão devem prever reflexões e leituras, estudos das categorias de NEE, estágios supervisionados na área e relações multidisciplinares na grade do curso de licenciatura.

Certamente, no terceiro momento, pôde ser detectada a sedimentação dos conceitos e representações sobre a inclusão bem como as relações práticas desvendando-se assim, para nós, enquanto pesquisadores, novas perspectivas. Esse terceiro momento de formação revelou um amadurecimento pedagógico profissional dos entrevistados que se mostraram mais atentos às questões da diversidade $\mathrm{e}$ da inclusão. Por exemplo:

- o olhar para uma inclusão que está atenta aos processos de ensino e aprendizagem de alunos com necessidades educacionais especiais, que não estão simplesmente no espaço da sala de aula para se dizer que se está fazendo inclusão;

- o reconhecimento de todas as principais categorias de NEE, pois quase $100 \%$ dos entrevistados (de um total de 36) participaram da aplicação do questionário.

- a necessidade, apontada pela maioria, de estágios supervisionados na área e a importância da 
temática da inclusão e da diversidade em todas as Licenciaturas e não apenas na Pedagogia.

As questões referentes aos estágios supervisionados e estruturas dos cursos de Pedagogia e outras licenciaturas pautados no educar na diversidade concordam com o trabalho de Tinos, Orlando e Denari (2008) que afirmam a falta de aprofundamento teórico nas temáticas da inclusão e educação especial.

Entendemos nesse sentido que o caminho a ser percorrido é bastante complexo e envolve um processo a médio e longo prazos em direção à desbarbarização adorniana da sociedade que perpassa, sem dúvida alguma, os currículos das licenciaturas que formam professores.

O estudo dessas representações é fundamental para a efetiva e real ação educativa inclusiva para diversidade estruturada nos cursos de formação inicial e em serviço: novas atitudes, novas formas de interação e mudança de relacionamentos pessoal e social.

\section{REFERÊNCIAS}

ADORNO, T.W. Educação e emancipação. Rio de Janeiro: Paz e Terra, 2006.

\section{ANDRÉ, M.E.D.A. Estudo de caso em pesquisa e avaliação educacional. Brasília: Liber Livro, 2005.}

BOURDIEU, P. Sociologia. São Paulo: Ática, 1983.

BUENO, J.G.S. As políticas de inclusão escolar: uma prerrogativa da educação especial? In: MENDES, G.M.L.; SANTOS, R.A. Deficiência e escolarização: novas perspectivas de análise. Araraquara, SP: Junqueira\&Marin; Brasília: CAPES, p.43-66, 2008.

BRASIL. Educar na Diversidade: Material de formação docente. $3^{\mathrm{a}}$ ed. Brasília: MEC/SEESP, 2006.
GOMES, C; REY, F.LG. Inclusão escolar: representações compartilhadas de profissionais da educação acerca da inclusão escolar. In: Psicologia: ciência e profissão. Brasília: Conselho Federal de Psicologia, v.27 n.3, p.406-417, 2007.

MICHELS, M.H. Práticas de ambiguidades estruturais e a reiteração do modelo médico psicológico: a formação de professores de educação especial na UFSC. In: BUENO, J.G.S.; MENDES, G.M.L.; SANTOS, R.A. Deficiência e escolarização: novas perspectivas de análise. Araraquara, SP: Junqueira\&Marin; Brasília: CAPES, p.205-250, 2008.

OLIVEIRA, E.S.G; COSTA, M. A. Currículo e cotidiano no trabalho com a diversidade: as metáforas representativas do professor de educação especial. In: MARQUEZINE, M.C.; ALMEIDA, M.A.; TANAKA, E.D.O. (orgs). Capacitação de professores profissionais para educação especial e suas concepções sobre inclusão. Coleção perspectivas multidisciplinares em Educação Especial. Londrina: Eduel, ), v.8, p.99100, 2003.

OMOTE, S. Inclusão: da intenção à realidade. Marília: Fundep, 2004.

PATTO, M.H.S. Políticas atuais de inclusão escolar: reflexão a partir de um recorte conceitual. In: BUENO, J.G.S.; MENDES, G.M.L.; SANTOS, R.A. Deficiência e escolarização: novas perspectivas de análise. Araraquara, SP: Junqueira\&Marin; Brasília: CAPES, ), p.25-42, 2008 .

PEREIRA, E.C.; MENDES, E.G. Necessidades educacionais especiais, diversidade, diferença e deficiência: percepções de docentes dos cursos de formação inicial de professores de Nível Médio. In: MARQUEZINE, M.C.; ALMEIDA, M.A.; TANAKA, E.D.O. (orgs.). Educação Especial: 
políticas públicas e concepções sobre deficiência. Coleção perspectivas multidisciplinares em

Educação Especial. Londrina: Eduel, v.5, p.43-54, 2003.

SOBRINHO, F.P.N.; NAUJORKS, M.I. (orgs.). Pesquisa em educação especial: o desafio da qualificação. Bauru: EDUSC, 2001.

SKLIAR, C. (Orgs.) Educação e exclusão: abordagens sócio-antropológicas em educação especial. 3. ed. Porto Alegre: Mediação, 2001.

TINOS, L.M.S; ORLANDO, P.A.; DENARI, F.E. Graduandos de pedagogia e suas concepções sobre a educação inclusiva. In: DENARI, F.E. (org.).

Igualdade, diversidade e educação (mais) inclusiva. São Carlos: Pedro \& João Editores, p. 197-215, 2008. 